\title{
PAP-Smear Study and its Utility in Cervical Cancer Screening in a Tertiary Care Hospital in Chittagong, Bangladesh
}

\author{
Sabina Yeasmin ${ }^{1 *}$ \\ Tahera begum' \\ Lutfun Naher Begum' \\ A.S.M. Mostaque Ahmed ${ }^{2}$ \\ Babul Osman ${ }^{2}$
}

'Department of Obstetrics and Gynecology Chattagram Maa-O-Shishu Hospital Medical College Chittagong, Bangladesh.

${ }^{2}$ Department of Pathology Chattagram Maa-O-Shishu Hospital Medical College Chittagong, Bangladesh.
${ }^{*}$ Correspondence to:

\section{Dr. Sabina Yeasmin}

Department of Obstetrics and Gynecology

Chattagram Maa-O-Shishu Hospital Medical College Chittagong, Bangladesh.

Mobile: +8801711110714

E-mail:cmoshctg@yahoo.com

\begin{abstract}
Background \& Purpose: In developing countries, cervical cancer is the most common gynecological cancer and one of the leading causes of cancer death. Cervical cancers can be prevented through early detection and cervical smear is a sensitive test for it. Materials \& Methods: This retrospective study was carried out at Chattagram Maa- Shishu O General Hospital, between July 2012 and June 2013. Total 500 patients were screened having complaints of vaginal discharge, irregular bleeding per vagina, post coital bleeding or something coming out per vagina. History and symptoms along with parity were recorded. Smears were taken by trained Doctor using modified Ayres wooden spatula and plastic endocervical cytobrush which were inserted and rotated 360 over cervix. Both ectocervix and endocervix were sampled. Slides were prepared, labeled, fixed in $95 \%$ ethyl alcohol immediately and subsequently stained by pap stain. After staining, slides were mounted with DPX (distren dibutyl phthalate xylene), screened and reported by two Cytopathologist according to The 2001 Bethesda system. Results: Age ranged from 20 to 50 and 50 to 75 years with an average age of 37 years. Four hundred sixty five $(93 \%)$ cases showed inflammatory lesions, $15(3 \%)$ showed atrophy, $8(1.6 \%)$ showed metaplasia and others showed ASCUS, AGUS, LSIL, HSIL, SCC. Eighty percent of all the epithelial abnormalities were found in the age group of 40 years and above. Average age of patients for all the epithelial abnormalities was 49years. Conclusion: Cervical cancer is one of the most common malignancies in the women of Bangladesh. Pap smear cytology is a useful screening tool to detect pre-invasive cervical epithelial lesions. Based on the findings of this study we recommend at least a single life-time Pap screening cytology of the uterine cervix of all the women aged 40 to 50 years.
\end{abstract}

Key words: Cervical cancer; screening; pap smea; bethesda system.

\section{INTRODUCTION}

Cancer of uterine cervix is a leading cause of mortality and morbidity among women worldwide. In developing countries it is the most common gynecological cancer and one of the leading causes of cancer death among women. Nearly 4 lacs new cases of cervical cancers are diagnosed annually worldwide and $80 \%$ of them are diagnosed in the developing countries. There are 1.7 million cases in the developing world and as many as 5-13 millions women have precancerous lesions ${ }^{1-2}$. According to National institute of cancer Research and hospital, Dhaka, (2005-2007) Cancers of uterine cervix and breast are leading malignancies seen in Bangladeshi women ${ }^{3}$.

Cervical cancers can be prevented through early detection using several screening techniques. Cervical smear is a sensitive test for early screening of the cervical lesion and most widely used system for describing PAP smear result is TBS[2001, The Bethesda System $]^{4}$. 


\section{MATERIALS \& METHODS}

The retrospective study was carried out at Chattagram MaaShish O General Hospital, during July 2012 to June 2013, total 500 patients were screened. The patients were having complaints like vaginal discharge, irregular bleeding per vagina, post coital bleeding or something coming out per vagina. History and symptoms along with parity were recorded.

Smears were taken by trained Doctor using modified Ayres wooden spatula and plastic endocervical cytobrush which were inserted and rotated 360 over cervix. Both ectocervix and endocervix were sampled. Slides were prepared, labeled, fixed in 95\% ethyl alcohol immediately and subsequently stained by pap stain. After staining, slides were mounted with DPX (distren dibutyl phthalate xylene), screened and reported by two Cytopathologist according to The 2001 Bethesda system.

\section{RESULTS}

Age ranged from 20 to 50 and 50 to 75 years with an average age of 37 years (Table 1). Four hundred sixty five (93\%) cases showed inflammatory lesions, $15(3 \%)$ showed atrophy, 8 (1.6\%) showed metaplasia and others showed ASCUS, AGUS, LSIL, HSIL, SCC (Table 2). Eighty percent of all the epithelial abnormalities (Table 3) were found in the age group of 40 years and above. Average age of patients for all the epithelial abnormalities was 49 years.

Table 1: Age-wise distribution of total number of patients.

\begin{tabular}{ccc} 
Age-group(years) & Number of patients & Percentage \\
$<20$ & 0 & 00.00 \\
$20-29$ & 150 & $30 \%$ \\
$30-39$ & 200 & $40 \%$ \\
$40-49$ & 107 & $21.4 \%$ \\
$50-59$ & 30 & $6 \%$ \\
$60-69$ & 12 & $2.4 \%$ \\
$>70$ & 01 & $.2 \%$ \\
Total & 500 & $100.00 \%$ \\
\hline
\end{tabular}

Table 2: Findings of Pap-smear cytology

\begin{tabular}{clcc} 
S.N. & Diagnosis & Number of cases & Percentage \\
\hline 1 & NRP* & 2 & $.2 \%$ \\
2 & Inflamation & 465 & $93 \%$ \\
& a) Mild & 257 & $51 \%$ \\
& b) Moderate & 102 & $20.4 \%$ \\
& c) Severe & 106 & $21.2 \%$ \\
3 & Ayrophy & 15 & $3.00 \%$ \\
4. & Metaplasia & 08 & $1.6 \%$ \\
5. & ASCUS & 01 & $0.2 \%$ \\
6. & AGUS & 03 & $0.6 \%$ \\
7. & LSIL & 01 & $0.2 \%$ \\
8. & HSIL & 03 & $0.3 \%$ \\
9. & SCC 02 & $0.4 \%$ & \\
& Total500 & $100.00 \%$ & \\
\hline
\end{tabular}

*NRP: No Remarkable Pathology.
Table 3: Age-wise findings of Pap smear cytology

\begin{tabular}{lcccccccc}
$\begin{array}{l}\text { Age group } \\
\text { (years) }\end{array}$ & Inflammation & Atrophy & Metaplasia & ASCUS & AGUS & LSIL & HSIL & SCC \\
\hline $20-29$ & 147 & 0 & 2 & 0 & 1 & 0 & 0 & 0 \\
$30-39$ & 198 & 0 & 1 & 0 & 0 & 1 & 0 & 0 \\
$40-49$ & 98 & 4 & 1 & 1 & 1 & 0 & 1 & 1 \\
$50-59$ & 18 & 7 & 1 & 0 & 1 & 0 & 1 & 0 \\
$60-69$ & 4 & 3 & 3 & 0 & 0 & 0 & 1 & 1 \\
$>70$ & 0 & 1 & 0 & 0 & 0 & 0 & 0 & 0 \\
Total & & & & & & & &
\end{tabular}

\section{DISCUSSION}

The incindence of cervical cancer has decreased more than 50\% in the past 30 years because of widespread screening with cervical cytology 5 . In 1975 , the rate was 14.8 per 100,000 women in the United States and by 2006, it had been reduced to 6.5 per 100,000 women. Mortality from the disease has undergone a similar decrease $\mathrm{e}^{6-8}$. Considering the efficacy of Pap smear cytology in preventing cervical cancer, it is advocated that it should be initiated in all women at the age of 21 years ${ }^{9}$.

The average age of patients in this study was 37 years.About $70 \%$ of the total cases are above the age of 30 years. This study reveals that Pap smear cytology is delayed by many years in the majority of women of this country.More education programs should be created to increase the awareness of the benefit of cervical pap smear.

In this study, there were 8 cases of abnormal epithelial lesions (1.6\%). The percenttage of epithelial abnormalities are $1.7 \%$ in Nepal, $2.3 \%$ to $6.6 \%$ in US, from $1.6 \%$ to $7.9 \%$ in the middle East, and $1.87 \% 5.9 \%$ in India ${ }^{10-11}$. The low incidence (1cases) of Atypical Squamous Cells of Undetermined Significance (ASCUS) in this study is possibly due to this lesion being commonly found in a younger age group. A similar findings was seen in Saudi Arabia ${ }^{12}$. Another reason for the overall low prevalence of abnormal epithelial lesions in this study is due to the small sample size.

A large scale study encompassing women from different strata and age group is required to determine the actual incidence of abnormal cervical epithelial lesions in Bangladesh.

According to National institute of cancer research and hospital, Dhaka, carcinoma of cervix was the third most common of all canecr cases and cancer cervix was the most common gynaecologic malignancy ${ }^{2}$. The HSIL was reported as high as 3.7\% Zimbabwe and China. Our study also showed HSIL and AGUS are the most common of all the abnormal epithelial lesions.

This study showed that the incidence of high grade epithelial lesions increases with the advancing age. Cancer of the uterine cervix should get priority in terms of control programs through mass screening in Bangladesh. In this study, $80 \%$ of all 
abnormal epithelial lesions were found in the age -group of 40 years and above and about $70 \%$ of the patients were above the age of 30 years (Table 3). A study done in India has found that $51.5 \%$ of HSIL cases and $75.3 \%$ of cancer cases were detected in women above 40 years of age ${ }^{13}$.

Based on our findings, and considering the paucity of resources in Bangladesh, it is proposed that women beyond 40 years be screened at least once in their lifetime to detect abnormal epithelial lesions. According to WHO recommendations (1986), screening at 45 years of age is the most correct approach, which could detect approximately $20 \%$ of total cervical cancer. 5 . The American Cancer condrol Program and the IARC have suggested similar or slightly modified screening programs ${ }^{14}$.

\section{CONCLUSION}

Cervical cancer is one of the most common malignancies in the women of Bangladesh. Pap smear cytology is a useful screening tool to detect pre-invasive cervical epithelial lesions. Based on the findings of this study we recommend at least a single life-time Pap screening cytology of the uterine cervix of all the women aged 40 to 50 years.

\section{DISCLOSURE}

All the authors declared no competing interest.

\section{REFERENCES}

1. Rejendra A Kalkar, Yongesh Kulkarini. Screening for cfrvical cancer : an verview. Obstet Gynecol India. 2006;56:2.

2. Mohammed Shaoaib Khan, Fohadiya Yasin Raja at el, Pap smear Screening for Precancerous conditions of the cervical cancers.Park J. Med. Res.2005;44(3):111-3.

3. National Institute of cancer Research and Hospital, Dhaka,Bangladesh,(2005-2007)

4. The 2001 Bethesda System; Terminology for reporting results of cervical Cytology.JMA 287, 2114, 2002.

5. The World Health Report, 1995 . Bridging the gaps . Geneva: World Health Organization; 1995.

6. Herrero R. Epidemiology of cervical cancer . J Natl Cancer Inst Monogr 1996; 21:1-6.

7. Eddy DM Screening for cervical cancer.Ann Intern Med 1990; 113:214-26

8. Van der Graaf Y, Klinkhamer PJ, Vooijs GP. Effect of population screening for cancer of the uterine cfrvix in Nijmegen, The Netherlands.Prev Med 1986; 15:582-90.

9. ACOG Practice Bulletin. Clinical management guidelines for obstetrician-gynaecologists; 2009.

10. Gamarra CJ, Paz EP, Griep RH: Knowledge, attitudes and practice related to Papanicolaou smear test among Argentina's women. Rev Saude Publica 2005; 39:2

11. Mulay K, Swain M, Patra S, Gowrishankar S. Comparative study of cervical smears in an Urban Hospital in India and a population- based screening program in Mauritius. Indian J Pathol Microbiol 2009; 52:34-7.

12. Abdullah LS. Pattern of abnormal pap smear in developing countries : A report from a large referral hospital in Soudia Arabia using the revised 2001 Bethesda system. Ann Saudi Med 2007; 27:268-72.

13. Misra S, Srivastava S, Singh U, Srivastava AN. Risk actors and strategies for control of carcinoma cervix in India:Hospital based cytological screening experience of 35 years. Indian J Cancer 2009;46:155-9.

14. Alliance for cervical cancer prevention (ACCP). Planning and implementing cervical cancer prevention and control programs: A manual for managers. Seattle: ACCP;2004. 